\title{
Study on Optimal Design of Digital Music Player Based on Human-computer Interaction
}

\author{
Yan Chen, Min Lv and LiWei Guo \\ Art Institute, Hebei Normal University of Science and Technology, Qinhuangdao, \\ 066004, China \\ 2067377625@qq.com
}

\begin{abstract}
Through the application of theories and principles of human-computer interaction design system, deficiencies on interaction of digital music player are analyzed; and through the analysis on cognitive features for interaction, hierarchy of needs, and emotional information of target users, the key factors and the relevant data that influence the objective of interaction design are researched, thus facilitating the modern digital music products design to follow up users' physical and mental requirements, balancing the interaction design between human, computer and environment, bringing users more convenient and effective operation and experience, and providing more important theoretical thought and implementation process for humanized design.
\end{abstract}

Key words: digital; music player; interaction design; optimization

\section{Introduction}

Along with the rapid development of electronic information technology, music player has stepped into an era with digital information instead of the past record player and tape drive as its main medium, and supporters of bulky single electronic devices are also replaced by intelligent, and small software players such as computer, mobile phones, MP3 and MP4 which have become an important part of human daily life. As a kind of multimedia player software, music player has playback tools for a variety of music formats, so it can be used to play all kinds of music files. With beautiful interfaces and simple operations, these playback tools can take users into a perfect music space. Most music players support various music formats such as MP3, WMA, MP4, ASF, AAC, Mp3Pro and MID, etc., the reason of which is that different audio decoders are packed and unified player interfaces are made in these music players in order to facilitate users to play and listen all kinds of music. However, many problems on human-computer interaction of music players still exist actually: 1) difficult human-computer interaction: a large proportion of players have gorgeous interfaces, but the practical operations of them are not so simple, which bring users lots of difficulties. Especially for beginners or new users, it's hard to operate them easily, quickly and effectively, which results to interactive difficulty between human and computer; 2) poor even no fault tolerance: faulty operations by some users in the process of usage can lead to unrecoverable wrong results, which may bring serious psychological burden to users; 3 ) low availability: sometimes users want to have some functions, which cannot be achieved in the actual design; etc. Through the theoretical research on human-computer interaction, and based on the analysis on users' cognitive features and need hierarchy, this paper explores the resolution procedures and optimization measures in aspects of availability, usability and fault tolerance of music player human-computer interaction, which plays an important guiding role in the relevant product interaction design $[1,2]$. 


\section{Human-computer Interaction}

Interaction design, as a new discipline focusing on interactive experience, was proposed originally as Soft Face in 1980s by Bill Moggridge who was the founder of IDEO. Afterwards Soft Face was renamed as Interaction Design by Bill Moggridge. Interaction design is a comprehensive subject, not only borrowing the theories and methods of traditional design, but also applying theories and technologies of availability design and Engineering Science. However, interaction design is never a simple superposition of all disciplines, but it has theories and research methods different from those of other engineering disciplines. Interaction design refers to a process of analyzing, forecasting, defining, planning, describing and exploring the interactive mechanism between products and users, namely a definition of artifacts' behavioral patterns. Interaction design focuses on users' experience, aiming at optimizing and expanding people's manners of working, communicating and interacting, and facilitating them to work and study more conveniently, efficiently and easily by the usage of products. In interaction design, the mode and sequence of options that will be presented to users need to be determined and options that will influence users' implementing and finishing tasks should be focused, which may sound very mysterious for us. However, it is actually not the matter of technology, but of understanding users as well as their working and thinking manners, through which knowledge about users is obtained and then added into the product's structure and performance so as to help guarantee users' experience. Through the interaction design on product interface and behaviors, an organic relation between product and its users can be established, as a result, users' goals will be achieved effectively, which is exactly the target of interaction design [3-6].

\section{Analysis on User Needs}

\subsection{Analysis on Human's Cognitive Features}

Cognitive process is a process of obtaining and processing information and people can be considered as an information processing system shown in Figure 1. In the cognitive process, external signals are firstly sensed by people through organs such as visual sense, auditory sense and tactile sense, etc.; then they will be transmitted to brain via nerve center; and signals will be selected and processed by brain and the feedback information is delivered to organs of locomotion via motor center; up to now, the whole information processing work is finished.

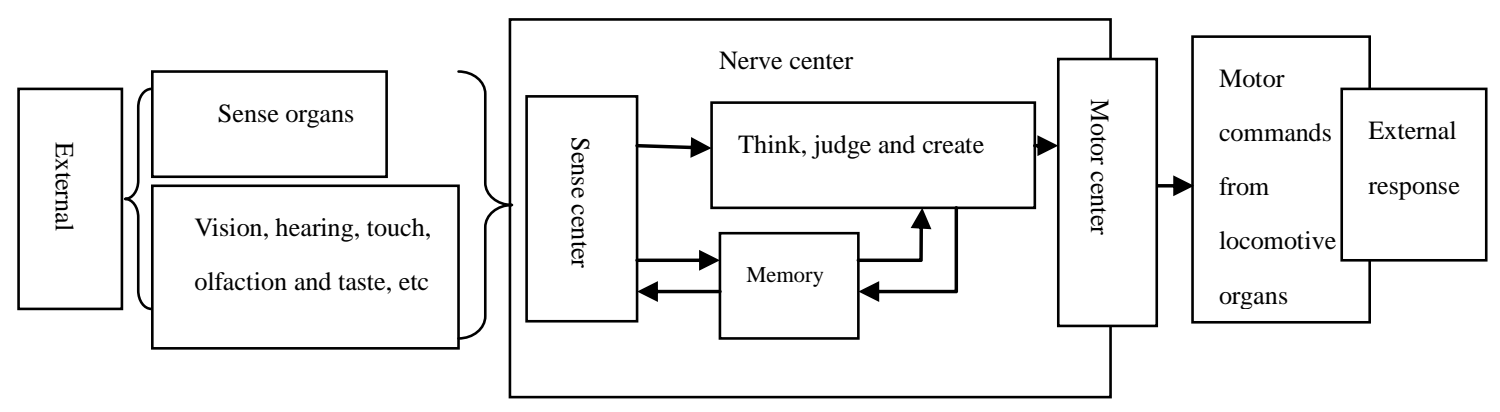

Figure 1. Sense Organs and Central Nervous System

The process of users' using the product is also a process of understanding and learning the knowledge on product's functions as well as a process of obtaining and processing information through the product's functional units. Users accept the signals from product operations via organs such as touch, hearing, and vision, etc., and deliver them to the cerebrum through nerve center for judging, thinking and processing, followed by that the feedback information will be transmitted from cerebrum to locomotive organs such as 
fingers and speech organs to operate the product. The above is the whole information processing process of users' using the product. In this process, whether the operations of product rationally and effectively conform to users' cognitive inertia or expectation is the most important index of judging the human-computer interaction design of product.

\subsection{Analysis on Users' Needs of Hierarchy}

In human-computer interaction, designers has been always focusing on needs of users, since the understanding degree for users' needs determines the satisfaction degree for users' physical and psychological needs in operating, using even appreciating the product. Abraham Maslow, a famous humanistic social psychologist in America, proposed creatively the hierarchy of needs theory in 1943 in the paper of "A Theory of Human Motivation". He divided human needs into five levels from low to high: Physiological needs; Safety needs; Love and belonging; Esteem; Self-actualization (see Figure 2) [7] [8].

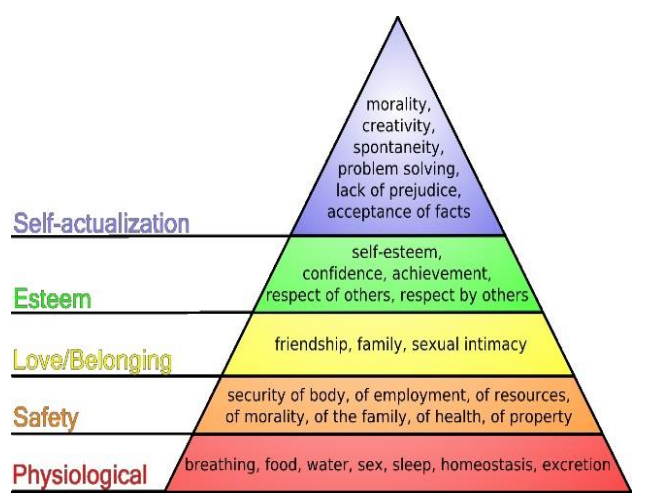

Figure 2. Maslow's Hierarchy of Needs

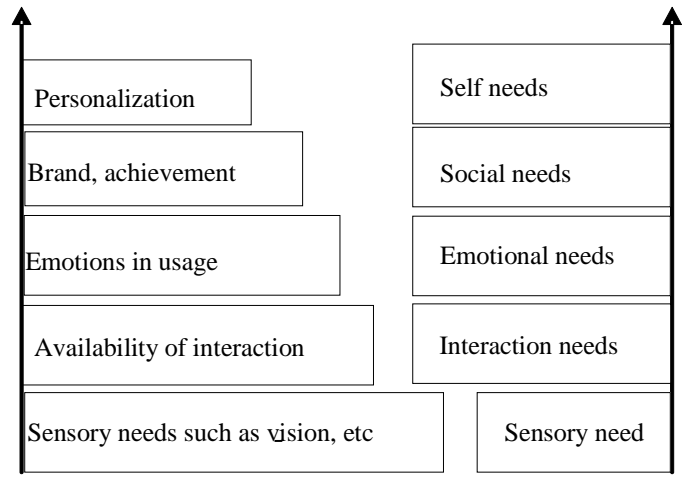

Figure 3 Hierarchy of Needs in Interaction Design

Then how is human's hierarchy of needs in interaction design? Is it the same to Maslow's hierarchy? In interaction design, users will change their needs to some extent in order to complete and enjoy the whole process of interaction. In Figure 3, the hierarchy of needs in interaction design is shown.

\subsection{Analysis on Human's Emotional Information}

In using the product, different information factors such as shape, color, material and texture may produce different psychological feelings for users who will accordingly adjust their psychological and physiological activities. When receiving stimulus from the product, the sensory organs will transmit it to the brain for analysis, judgment and decision-making through the nervous system, and then send an instruction to organs controlling emotions through nerve endings where nerve fibers are output, thereby transforming it into the external manifestations of the operator's emotions. Above is the whole process of human body's processing emotional information. And the procedure of "sense $\rightarrow$ judgment $\rightarrow$ behavior $\rightarrow$ manifestation" constitutes a processing system of information interaction between the product and the user $[9,10]$.

Through the above emotional information processing system, physical sensation channels of product interaction that are closely related to the emotional organ functions can be summed up. And the information transmission ability of each sensory channel has certain performance limit. Data on different interaction design interfaces show that the human emotional performance is influenced tremendously. Table 1 gives the evaluation standard of sensation channels for different emotional information [11-13]. 
Table 1. Evaluation Standard of Emotional Channel for Product Physicality

\begin{tabular}{|c|c|c|c|c|c|c|c|c|c|c|c|}
\hline \multirow{2}{*}{$\begin{array}{l}\text { Product } \\
\text { interaction }\end{array}$} & \multicolumn{3}{|c|}{ button shape } & \multicolumn{4}{|c|}{ Color mode } & \multicolumn{4}{|c|}{ Texture feedback } \\
\hline & Streamlined & Angular & Abnormal & $\begin{array}{c}\text { Bright } \\
\text { color }\end{array}$ & $\left|\begin{array}{l}\text { Neutral } \\
\text { color }\end{array}\right|$ & $\begin{array}{l}\text { Gray } \\
\text { color }\end{array}$ & $\begin{array}{l}\text { Black } \\
\text { color }\end{array}$ & Frosted & Smooth & Metallic & Glass \\
\hline $\begin{array}{l}\text { Visual reaction } \\
\text { time }(\mathrm{s})\end{array}$ & $0.1 \sim 0.2$ & $0.1 \sim 0.3$ & $0.3 \sim 0.4$ & 0.13 & 0.44 & 1.30 & 0.53 & 0.53 & 0.44 & 1.08 & 0.30 \\
\hline $\begin{array}{l}\text { Emotional } \\
\text { association }\end{array}$ & $\begin{array}{l}\text { speedy } \\
\text { cute } \\
\text { cheerful }\end{array}$ & $\begin{array}{l}\text { virile } \\
\text { regular } \\
\text { stable }\end{array}$ & $\begin{array}{l}\text { peculiar } \\
\text { skeptical } \\
\text { reflective }\end{array}$ & $\begin{array}{c}\text { Warmth } \\
\text { active }\end{array}$ & calm & low & $\begin{array}{l}\text { Rueful } \\
\text { dreary }\end{array}$ & Natural & $\begin{array}{l}\text { machining } \\
\text { smooth }\end{array}$ & $\begin{array}{c}\text { ice-cold } \\
\text { tough } \\
\text { durable }\end{array}$ & $\begin{array}{c}\text { transparent } \\
\text { clean } \\
\text { fragile }\end{array}$ \\
\hline $\begin{array}{l}\text { Positive } \\
\text { emotions }\end{array}$ & $\begin{array}{c}\text { happy } \\
\text { pleasant } \\
\text { appreciative }\end{array}$ & $\begin{array}{c}\text { safe } \\
\text { effective } \\
\text { comfortable }\end{array}$ & $\begin{array}{l}\text { imaginative } \\
\text { desirous } \\
\text { interesting }\end{array}$ & Happy & 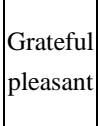 & N/A & safe & pleasant & $\begin{array}{l}\text { happy } \\
\text { curious }\end{array}$ & $\begin{array}{c}\text { confident } \\
\text { envious }\end{array}$ & $\begin{array}{l}\text { Cheerful } \\
\text { desirous }\end{array}$ \\
\hline $\begin{array}{l}\text { Negative } \\
\text { emotions }\end{array}$ & skeptical & afraid & annoying & N/A & boring & dejected & afeard & plain & annoying & N/A & anxious \\
\hline
\end{tabular}

\section{Human-computer Interaction Optimization of Digital Music Player}

Through the research on human-computer interaction, target users and user needs, we can know that digital music player in human-computer interaction system includes mainly the following three factors:

\subsection{Availability of Digital Music Player}

In designing digital music player, the meaning of applicability is expanded. Basically, it refers to that the player should meet the requirements of specific users for the fundamental functions. Besides, on the premise of meeting its use functions, the player should also be expanded for its scope and function demands of scheduled users as far as possible.

\subsubsection{Availability of Functions}

Availability of functions mainly refers to that a player can achieve the auditory appreciation purpose of the basic target users. Design elements shall conform to users' psychological features which not only include the completion of auditory appreciation in use, but also include the psychological comforts such as agreeableness and intimacy. Therefore, in design, the semantic application of product colors and materials are particularly important. Physiological availability is mainly reflected in the process of usage. At the beginning of design, it is particularly important to study on the music appreciation approach. Only by finding the most appropriate design approach according to the characteristics of user needs can the proper device be designed. The research factors on availability of functions mainly include the operation method, use environment, use scope, motor pattern and range, etc.

\subsubsection{Availability of Application Scope}

Availability of application scope mainly refers to the expansion of music player's use scope and special use groups based on the meeting of a specific function. In the process of using players, operation requirements of special groups such as people with incomplete upper limb function or people with impaired hearing should also be fully considered. Therefore, the function extension of music player is mainly reflected in that the function design should not only meet the demands of common people, but also of specific and special groups. 


\subsubsection{Precautions in Availability Design}

The applicability of product is to research on the most appropriate interaction mode or method between the equipment and human from the perspective of human-computer relation, and to determine the most reasonable method of using the product or equipment. A reasonable usage method is a main standard of measuring product functions and forms. In use, the music player itself and its environmental condition can reduce people's physical and mental pressure, but the listening time and frequency shouldn't be too long and high, which should be controlled by the limitation mode interface. As a result, human auditory load resistance must be taken into consideration in digital music player design to accommodate users' physiological and psychological features and to be limited in the comfort range of human body, which is also the reflection of humanized design. Based on human biomechanics and according to different needs and psychological features of different users, the following points that are suitable for users shall be considered in the design:

1) Simple and reliable operation interface;

2) Reasonable and even touch force, and give feedback timely;

3) Stable and reasonable operating speed and response speed;

4) Proper operating angle and mode;

5) Proper musical beats and accuracy of operation.

Voice is a very detailed and clear expression of delivering information between human and computer, and music can meet people's requirements of interest and comfort better in interaction design. Therefore, in the process of design, the relation between age, optimal visual distance, optimal operation size and the displayed maximum number I on interface as are shown in Figure 4, 5 and 6 should be considered adequately.

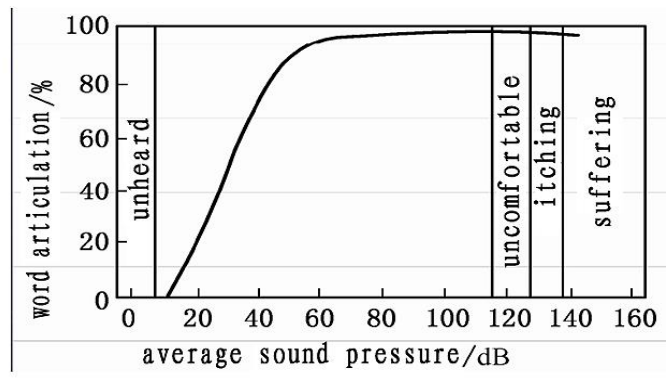

Figure 4. Relation between Tones and Comfort

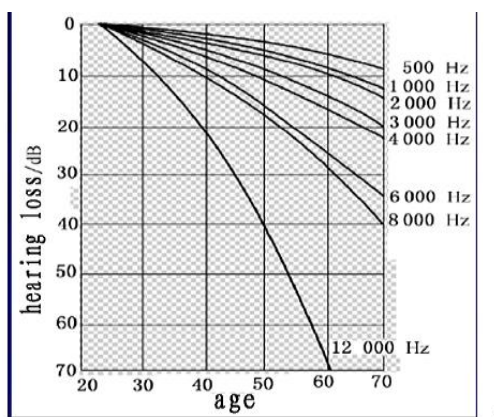

Figure 5. Relation between Age and Hearing Loss

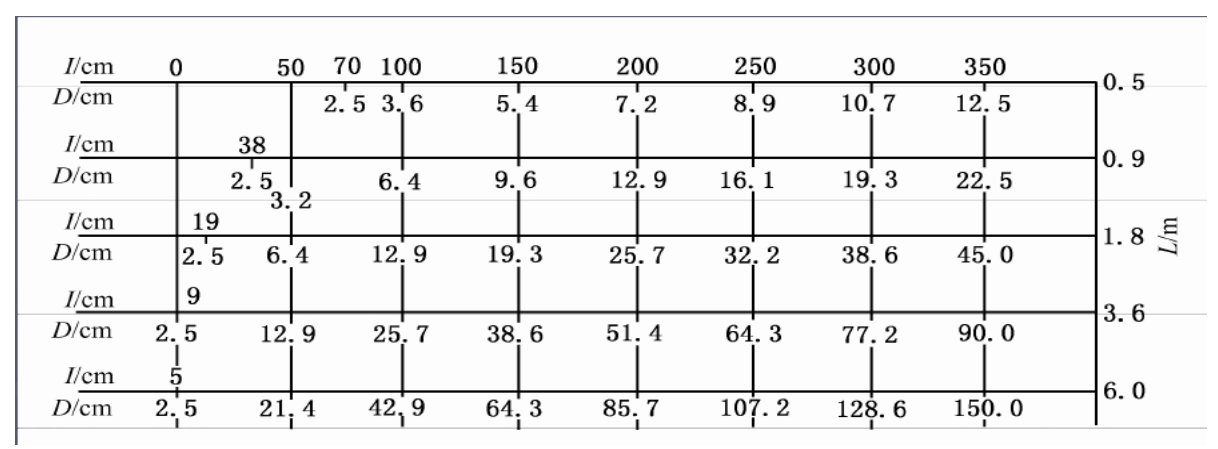

Figure 6. Maximum Number I in Interface Design 


\subsection{Usability of Digital Music Player}

In ISO 9241-11, usability is defined as "to some extent, a product can be used by specific users in specific fields with its performance for some purpose being achieved effectively, efficiently and satisfactorily." Usability in this paper refers mainly to the usability of music players. Concerning of the specific design of digital music player device, the product itself shall conform to the physical sizes of target users, and its shape and color processing should have an affinity for users and facilitate them to be clear for the operation method at a glance. Figure 7 shows the relation between view shed and optimal visual interaction.

\subsubsection{The Relevant Factors of Usability}

The usability of this product should be analyzed from the following aspects:

1) Guess ability which refers to the degree of help provided by the product to the user in his/her first use in order to complete a particular function;

2) Learn ability which refers to the degree of help including self-learning and training receipt provided by the product to the user from the first use to becoming a experienced user;

3) Experienced user performance which refers to the degree of guarantee provided by the product to the experienced user in order to successfully complete a particular operation;

4) System potential which refers to the possibility degree of selection for different means provided correspondingly by the product to users with different proficiency in order to complete a particular function;

5) Re-usability which refers to degree of help provided by the product to the user after a relatively long period of time in order to successfully complete a particular operation once again.

The above five criteria can help designers take a full consideration in initial product design, and can also serve as good testing standards for interaction degree of product usability. In the process of achieving product usability, the following three common constraints shall be taken into consideration:

Semantic constraint: it refers to that possible operation methods can be constrained by applying the meanings in some situations. Semantic constraint relies on our understanding of the situation and the outside world which may provide very effective and important operation clues. When people are using a product, they understand the product based on visual clues as every product and every button can "speak out" its meaning and "tell" about its operation goals and the correct operation methods through the symbol of structure, shape, color, material and position. For example, circle means "rotation", and red means "danger", etc.

Cultural constraint: it refers to that the operation methods of products can be constrained by some cultural practices that have been accepted by people. Each culture has its own code of social conduct. In the process of using the new product, difficulties we encountered are rooted mostly in cultural factors as we couldn't find temporarily a set of widely accepted cultural practices. Experts in this field believe that the cultural code of conduct is reflected in our minds in the form of archetypes, and knows people's behaviors.

Logic constraint: it refers to the constraint where natural matching rules are applied. In this situation, there is no physical and cultural norm between the product parts and things that are influenced or influence the product parts, but there is logic relation between the two spatially and functionally. The proper application of logic constraint can reduce labels 
as far as possible and can facilitate users to operate conveniently. The natural logic is shown in Table 2.

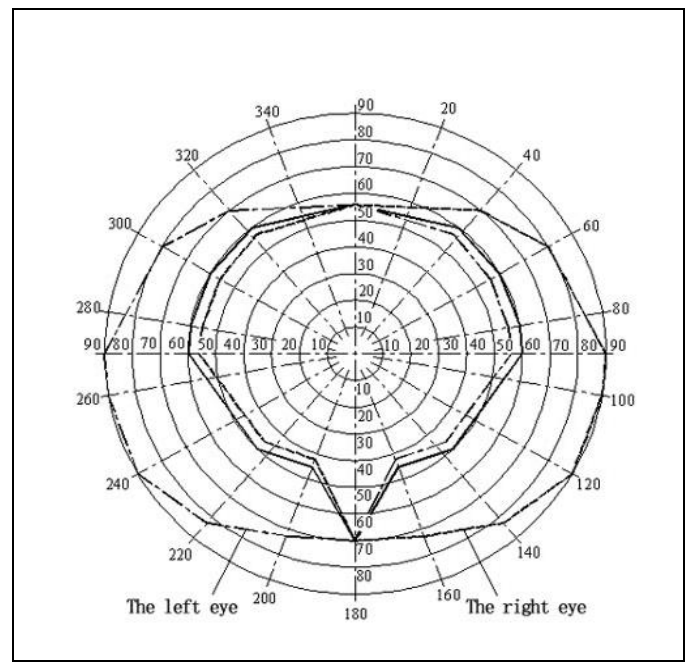

\section{Figure 7. Relation between View Shed and Optimal Visual Interaction}

\section{Table 2. Natural Logic}

\begin{tabular}{|c|c|}
\hline On & Rightward, forward, clockwise \\
\hline Off & Leftward, backward, anticlockwis \\
\hline Right shift & Rightward, clockwise \\
\hline Left shift & Leftward, anticlockwise \\
\hline Up & Upward, backward \\
\hline Down & Downward, forward \\
\hline Retract & Pull backward and upward \\
\hline Protrude & Push forward and downward \\
\hline Increase & Upward, rightward or clockwise \\
\hline Reduce & Downward, leftward or anticlockwise \\
\hline
\end{tabular}

\subsubsection{Measures of Improving Usability}

In order to improve the product usability, the following measures shall be taken: adhering to target user-centered design; focusing on product visibility; establishing correct matching relationships; strengthening restrictive design; and applying standardization rationally.

1) Focusing on product visibility: designers shall focus on the visibility of product appearance and present the product functions and use methods to target users by applying styling elements such as shape, color and texture, etc. As a result, target users will understand and learn how to operate in use at the beginning.

2) Establishing correct matching relationships: matching, namely consistency, here refers to consistency between product use status and status desired by users. That is to 
say, there should be correct feedback information of product to be delivered to users through means of vision, hearing and touch, etc. Besides, the feedback information should conform to users' intention and be manifested in the way that users can understand. Experiments show that it is the fastest way to deliver feedback information by the application of icons which can be easily and correctly recognized. For example, in the design of music player, interface display can change along with the force or damping, and the change trends of two are consistent.

3) Strengthening restrictive design: designers shall take full account of all the possible mistakes users may make and render target users have only one option by applying various constraints in order to avoid faulty operations.

\subsection{Research on Fault Tolerance of Music Player Design}

\subsubsection{Factors Inducing Faulty Operations}

From the perspective of psychology, Reason defined human error as such phenomenon that although human conducted a series of designed psychological operations or physical activities, the expected results were not reached, which cannot be attributed to the intervention of external factors. In accordance with the principles of human behaviors, it is known that human errors are mainly: errors when human perceive environmental information; decision errors made by human brain while processing the information; errors when outputting behaviors, etc. As a result, it's easy to make mistakes in the human-computer interface design of music player. Table 3 shows the types of error.

\section{1) Cognitive factors}

Cognition refers to the process of obtaining, applying or processing information by human. Information processing process or cognitive process is that: firstly human brain receives information from outside that will be processed by mind; and then the processed information is turned into internal psychological activities which dominate human behaviors in turn. Cognitive functions include perception, attention, memory and decision, etc.

\section{2) Physiological factors}

As a realistic organism, human cannot be arbitrary and perfect. Some human errors are resulted from human physiological restrictions such as physical boundaries, reaction speed limits, and the boundaries of biological rhythms, etc. Physiological factors include individual sizes, senses, thinking, memory, physical strength, endurance, motor function, reaction ability, physiological tolerance and biological rhythms, etc.

3) Psychological factors

Any production activities need the participation of human who as a realistic reflection of consciousness is dominated by psychology. A good psychology is helpful and positive, which can reduce the occurrence of human incidents. Psychological factors include motivation, psychological tolerance, ignorance, fast-seeking, rebellion, and habits, etc. 
Table 3. Types of Error

\begin{tabular}{|c|c|c|}
\hline \multirow{7}{*}{ Operations } & \multirow{7}{*}{$\begin{array}{l}\text { Faulty operations } \\
\text { Faulty settings } \\
\text { Faulty maintenance }\end{array}$} & Improper or incomplete technical data \\
\hline & & Improper equipment and maintenance \\
\hline & & Improper training or skills \\
\hline & & Unfinished ergonomic design \\
\hline & & Improper environment \\
\hline & & Overloaded conditions \\
\hline & & Excessive complexity of tasks \\
\hline
\end{tabular}

\subsubsection{Methods for Fault Tolerance of Music Player Design}

To summarize and conclude, methods of fault tolerance in designing digital music players are proposed as follows:

\subsubsection{Optimizing the Human-Computer Interface Design}

Hardware and software interface design: clear and easily identified text fonts with larger size, stronger color contrast and higher brightness; convenient and reliable operation with operating tips or feedback information display and less learning and memory time; simple and easily understood icon design with clear meanings and less icons of complex graphics as far as possible; zoning control panel according to function in order to avoid faulty operations; larger buttons to accommodate the disabled and elderly people who have such physiological characteristics as action inaccuracy, vision loss and other; obvious materials for panel design in order to divide functions for buttons according to different textures; easily identified color with strong contrast; less user memory by designing shortcut keys. Figure 8 and 9 show the simple, easily operated and interaction pleasant design projects of music player interface and operation interface.

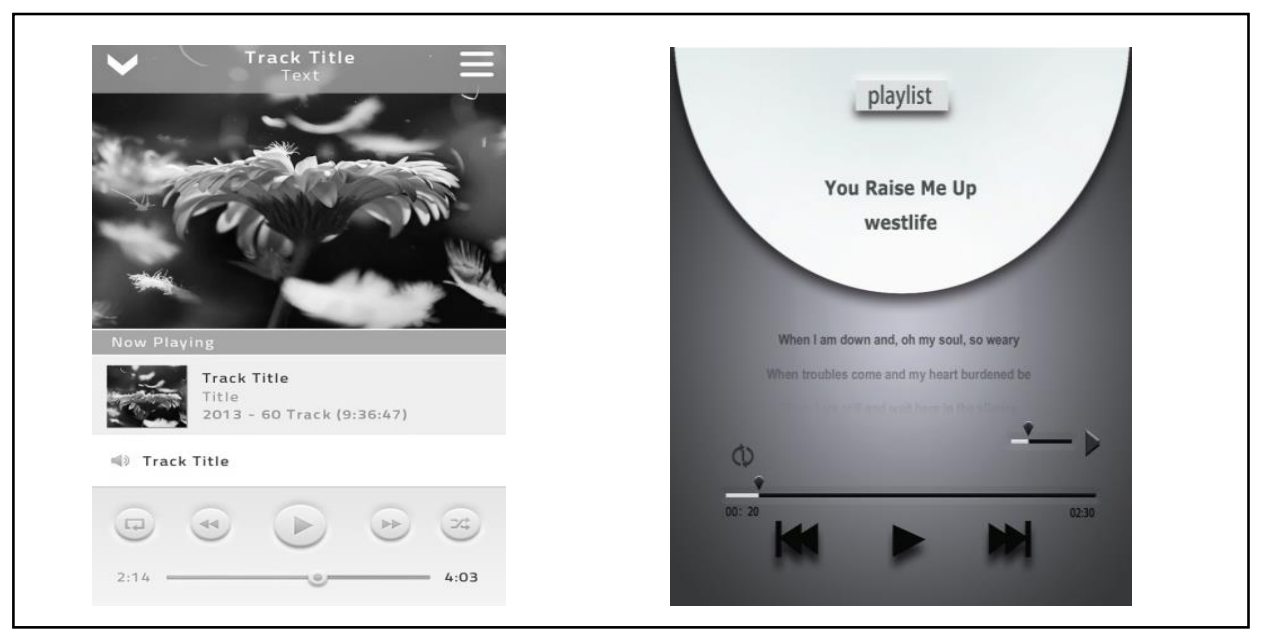

Figure 8. Interface Design Project of Music Player 


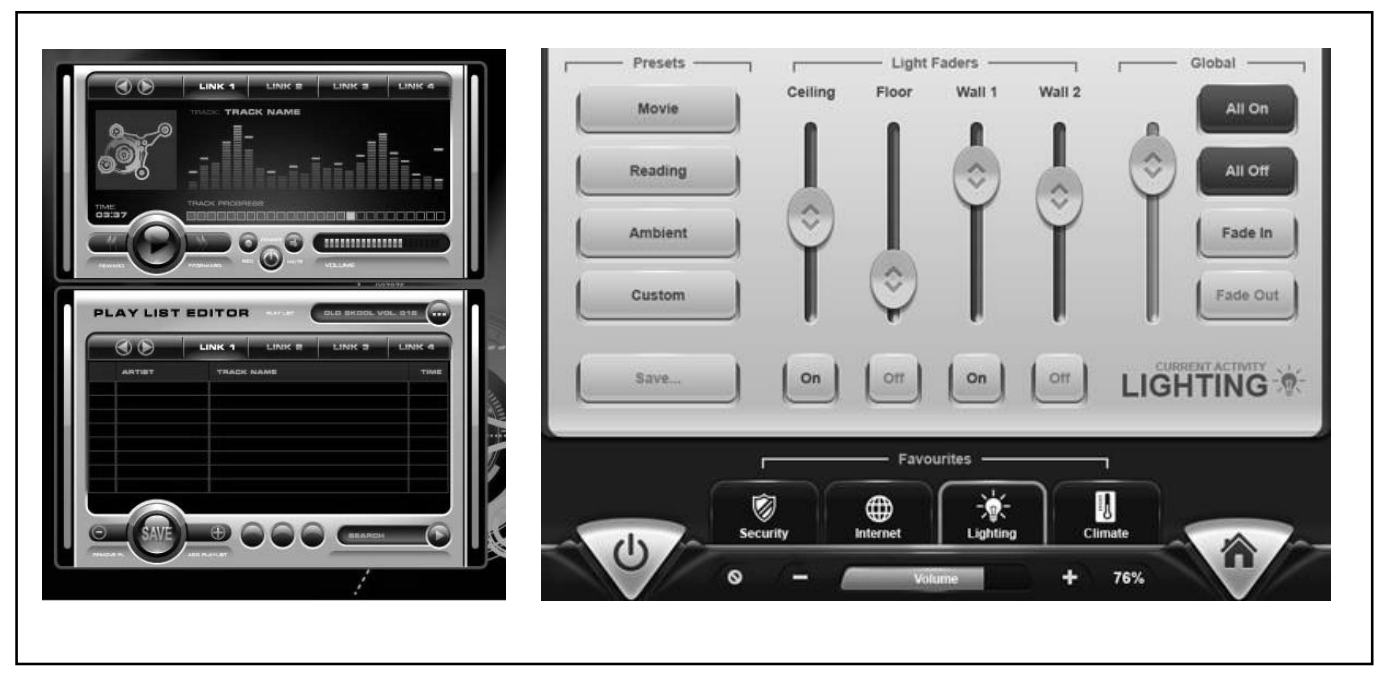

Figure 9. Operation Interface Design Project of Music Player

\subsubsection{Improving the Environmental Conditions that Easily Induce Faulty Operations}

Environmental factors that may result to human error of operation include product-use environmental conditions and use space, etc. Environmental factors can directly influence the judgment of human brain. The fatigue characteristics of human body and the activity rhythm of organism such as human function system and functional organs are likely to be physiological reasons for the occurrence of human errors. Besides, the influence of physiological activity rhythm of the human brain, especially the level of consciousness, on human behavior and human error should not be ignored particularly. Therefore, when improving the use conditions of music player, it should be noticed that the environment should be quiet and the color should not be too rich in order to avoid users' psychological irritability which may induce faulty operations.

\subsubsection{Offering Convenient and Comfortable Conditions in Operating, Maintaining and Adjusting Music Players}

This is mainly about the structure and shape of music player design. In the process of operating a music player, not only the needs of rehabilitation shall be met, but also the operation process be completed simply and easily. For example, during damping training, the resistance shall be consistent and even; and there shall be no noise in the process.

\subsubsection{Reasonable Ergonomic Design}

In developing and designing music player products, the following contents shall be focused and taken into account: sizes of human body parts; operating postures of human and their physical features; human actions and rhythm; human features of exercise physiology, sense physiology, psychology and reaction; cognitive and motion characteristics of different people; control system and its coordination of music player products; energy consumption of human body and human-computer effect in human-computer control system, etc.

\section{Conclusion}

Through the research on principles and logic analysis of human-computer interaction system based on users, this paper dissected the deficiencies that digital music players have regarding interaction; studied in particular the relationship between cognitive features and user needs, as well as between user behaviors and user environment of target users in 
interaction design; proposed solutions and measures for the key factors such as availability, usability and fault tolerance in the interaction design of modern digital music player; researched creatively on the data sources, methods and general procedure of task analysis in interaction design, which indicated a clear direction for task analysis of interaction design at practical level; and finally applied the research results to the revision cases of music player interface designed by the author, which verified strongly the value of research results.

\section{References}

[1] J. B. Li and B. H. Xu, "Synthetic assessment ofcognitive load in human-machine interaction process", ActaPsychological Sinica, vol. 29, no. 2, (2010), pp. 64-67.

[2] B. Chris, L. Daniel and Y. Alan, "EEG correlates of task engagement and mental workload in vigilance,learning, and memory tasks", Aviation, Space, and Environmental Medicine, vol. 7, no. 8, (2011), pp. 231-244.

[3] Z. Ye, Y. Li and B. Han, "Appearance Design Evaluation on CNC Machine Tools Basedon Fuzzy Synthetic Evaluation Model”, International Journal of Multimedia and Ubiquitous Engineering, vol. 9, no. 2, (2014), pp. 65-76.

[4] F. Paas and van Merrienboer, "Instructional control of cognitive load in the training of complex cognitive tasks", Educational Psychology Review, vol. 6, (2012), pp. 351-371.

[5] D. Ru-Wei, "Metasyntactic wisdom of man computer coopera-tion", Pattern Recognition and Artificial Intelligence, vol. 7, no. 3, (1994), pp. 181-190.

[6] Z. Shu-Hao and H. Wen-Qi, "Computer aided design for the problem of geometric distribution", ACTA Mathematicae Ap-plicatae Sinica, vol. 6, no. 1, (2014), pp. 34-46.

[7] X. De-you, "Hand Gesture-based Interaction in Virtual Reality Training System", Journal of System Simulation (S1004-731X), vol. 18, no. 2, (2006), pp. 386-389.

[8] I. S. Kim, "Human reliability analysis in the man-machine interface design review", Annals of Nuclear Energy, vol. 28, (2001), pp. 1069-1081.

[9] Z. Ping-ping, Z. Li and J. Jian, "junEffects of Complexity of Human Machine Interaction on Human Error in Digital Control System”, Journal of University of South China, vol. 14, no. 5, (2013), pp. 78-81.

[10] Z. Li, W. Yiqun and D. Zhiliang, "Human Errors In Complex Man-Machine Systems", China Safety Science Journal, vol. 6, no. 6, (1996), pp. 35-38.

[11] M. Paz Barroso and J. R. Wilson, "Human Error and Disturbance Oc2 currence in Manufacturing Systems (HEDOMS): A Frame2 work and a Toolkit for Practical Analysis", Cognition Technology \& Work, vol. 2, (2000), pp. 51-61.

[12] L. Chengpeng, "Using VBA to design curved surface based on CATIA software", Journal of Guizhou University: NaturalScience, vol. 24, no. 5, (2007), pp. 495.

[13] J. H. Lee, "Stimulating designers' creativity based on a creative evolutionary system andcollective intelligence in product design”, International Journal of Industrial Ergonomics, vol. 40, no. 3, (2010), pp. 295-305

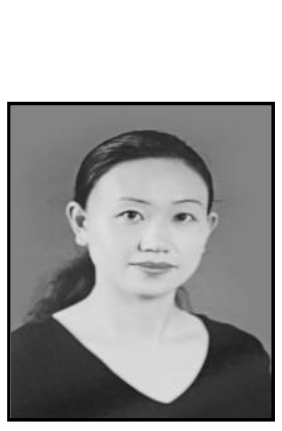

\section{Authors}

Yan Chen, Graduated from the Conservatory of Music, Hebei Normal University majoring in musicology and got the master's degree in 2003. Working in the Arts Department, Hebei Normal University of Science and Technology as a teacher and researching on musicology, music theory teaching and creation technique for computer music.

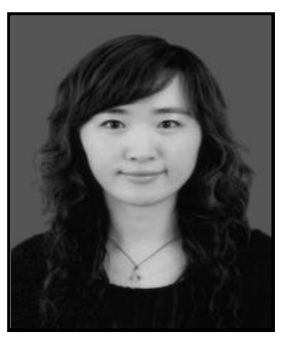

Min Lv, Graduated from northeast normal university, the research direction of musicology, now the Hebei normal university of science and technology in China 
International Journal of Signal Processing, Image Processing and Pattern Recognition Vol. 8, No. 1 (2015)

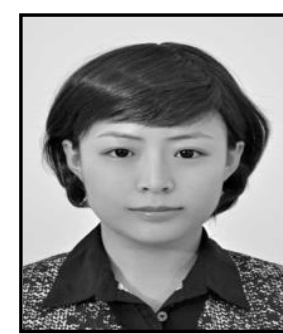

Liwei Guo, Graduated from northeast normal university, the research direction of musicology, now the art institute of Hebei normal university of science and technology in China 